\title{
ANALYSIS \\ Comparing augmented sustainability measures for Scotland: Is there a mismatch?
}

\author{
John C.V. Pezzey ${ }^{\mathrm{a}, \mathrm{b}, *}$, Nick Hanley ${ }^{\mathrm{c}}$, Karen Turner ${ }^{\mathrm{d}}$, Dugald Tinch ${ }^{\mathrm{c}}$ \\ ${ }^{a}$ Centre for Resource and Environmental Studies, Australian National University, Canberra, ACT 0200, Australia \\ ${ }^{\mathrm{b}}$ Department of Economics, University of Bath, BA2 7AY, England \\ ${ }^{\mathrm{c}}$ Department of Economics, University of Stirling, Stirling, FK9 4LA, Scotland, United Kingdom \\ ${ }^{\mathrm{d}}$ Fraser of Allander Institute, University of Strathclyde, Glasgow, G4 OLN, Scotland, United Kingdom
}

Received 17 July 2004; received in revised form 1 March 2005; accepted 18 March 2005

Available online 28 July 2005

\begin{abstract}
We estimate and compare two empirical measures of the weak sustainability of an economy for the first time: the change in augmented Green Net National Product (GNNP), and the interest on augmented Genuine Savings (GS). Yearly calculations are given for each measure for Scotland during 1992-1999. Augmentation means including, using projections to 2020, changed production possibilities enabled by exogenous technical progress or changing oil prices. The change in augmented GNNP and the interest on augmented GS are both always positive, showing no sustainability problem for Scotland then, according to the assumptions underlying our weak sustainability calculations. However, the former greatly exceeds the latter, even when macroeconomic fluctuations are taken into account. This is a mismatch which poses an unresolved problem with the theory. Resolving it may require respecifying the utility functions used in mainstream growth theory.
\end{abstract}

(C) 2005 Elsevier B.V. All rights reserved.

Keywords: Sustainability; Scotland; Genuine savings; Green NNP; Augmentation

\section{Introduction}

Sustainable development is now an important policy priority for many EU countries, and recent years have seen much interest in improving country-level ("macro") indicators of "sustainability". Many deve-

\footnotetext{
* Corresponding author. Centre for Resource and Environmental Studies, Australian National University, Canberra, ACT 0200, Australia. Tel./fax: +612 6125 4143/0757.

E-mail address: pezzey@cres.anu.edu.au (J.C.V. Pezzey).
}

lopments have recently been made in the economics of sustainability, particularly the theory and practice of measuring weak sustainability for a whole country under standard neoclassical assumptions of presentvalue maximisation by a representative agent, and substitutability in consumption and production. For theory, we refer particularly to Weitzman (1997), Vincent et al. (1997), Pemberton and Ulph (2001), Asheim and Weitzman (2001, hereafter AW) and Pezzey and Toman (2002, hereafter PT); see also Asheim (2003) for a comprehensive taxonomy of 
results, and Pezzey (2004) for an extension to include population growth, though this is not included in our model here. AW showed that in a theoretical, presentvalue-maximising economy, two measures are always equal: the time derivative of real, Green Net National Product (GNNP), and Genuine Savings (GS), a measure of aggregate net investment across the whole economy, multiplied by the real interest rate. PT used this result to show a "one-sided" theoretical result, that if either measure is zero or negative at some time, the economy is unsustainable then; they also "augmented" AW's and their own results to include terms for exogenous changes in production possibilities over time.

In this paper we apply and test the combined AW/ PT results empirically for the first time, by estimating augmented GNNP and the interest on augmented GS for Scotland for the period 1992-1999. The augmentation terms that we include, using projections or scenarios up to 2020, are exogenous technical progress, as inspired by Weitzman's estimation of this for the USA; and changing terms of trade in oil, as inspired by Vincent et al.'s estimation of this for Indonesia as an oil-exporting economy.

The two resulting series of one-sided sustainability measures (augmented GNNP and interest on augmented GS) then tell us some, but not all, of several things. If the series are broadly similar in sign and magnitude, they support the theory, and tell us roughly how (weakly) sustainable Scotland was during this period; we will also find how significant the augmentation terms are within the total. The two series will also provide an interesting comparison with Hanley et al. (1999), who estimated GNNP and GS (among other measures) for Scotland for 1980-1993, but neither included any augmentation terms nor compared GNNP change with the interest on GS. If the two series are very different in size - what we call a "mismatch problem" - this may suggest a need to respecify parts of the theory used to derive these empirical indicators, such as the type of utility function used, which is inherently hard to test and has often been questioned by ecological economists and economic psychologists. However, we shall see that macroeconomic fluctuations also complicate the testing of optimal growth models with real data, and make it hard to be sure about differences in size. And of course there can be grey areas in-between the two series being "broadly similar" or "very different".
Section 2 of the paper summarises an existing general theoretical model of national income accounting and sustainability. Section 3 describes a more specific model with realistic features, to be estimated for Scotland. Section 4 describes the data sources used for Scotland. Section 5 gives the empirical results. These indeed reveal a mismatch problem, which we subject to three sensitivity tests. Section 6 concludes.

\section{A general theoretical model}

This is as in Sections 3.1 and 3.3 of PT, which we now summarise. In an economy with smooth production sets and utility functions, which thus falls within the neoclassical or "weak" paradigm of sustainability measurement, augmented Green Net National Product (GNNP) and augmented Genuine Savings (GS) are defined in real Divisia prices at time $t$ as

$$
\begin{aligned}
& Y^{\dagger}(t) \quad:=\mathbf{P}(t) \cdot \mathbf{C}^{*}(t)+\mathbf{Q}^{\dagger}(t) \cdot \dot{\mathbf{K}}^{* \dagger}(t) \\
& \text { augmented }:=\text { consumption }+ \text { augmented } \\
& \text { GNNP expenditures GS. }
\end{aligned}
$$

Here, $\mathbf{C}(t)$ is an extended consumption vector, including amenities, which determines the representative agent's instantaneous utility $U[\mathbf{C}(t)] . \mathbf{K}^{\dagger}:=(\mathbf{K}, t)$ is the vector $\mathbf{K}(t)$ of the economy's controlled, productive stocks of capital (physical, financial, natural, human, knowledge, etc.), together with time $t$, treated as an uncontrolled stock which causes changes in production possibilities, as in Pemberton and Ulph (2001), for example from exogenous technical progress or shifts in terms of trade. Any variable containing or corresponding to time as a stock will be called augmented and denoted by ${ }^{\dagger}$. The economy is assumed to choose $\mathbf{C}$ and $\dot{\mathbf{K}}$ to be dynamically efficient, defined as maximising present value $W\left\{(\mathbf{C}(t)\}:=\int_{0}^{\infty} U\right.$ $[\mathbf{C}(t)] \mathrm{e}^{-\rho t} d t$ s.t. $\left[\mathbf{C}(t), \dot{\mathbf{K}}^{\dagger}(t)\right] \in \Pi\left\{\mathbf{K}^{\dagger}(t)\right\}$, where the utility discount rate $\rho$ is positive and constant, and $\Pi\left\{\mathbf{K}^{\dagger}(t)\right\}$ is the economy's production possibilities set. The maximising paths are then $\mathbf{C}^{*}$ and $\mathbf{K}^{* \dagger}$ as in (1); and included in this maximising assumption is that the economy always fully utilises its factors of production, so that macroeconomic fluctuations such as business cycles are excluded. $\mathbf{P}$ and $\mathbf{Q}^{\dagger}:=\left(\mathbf{Q}, Q^{t}\right)$ are the vectors of real Divisia accounting prices for 
consumption and capital, with $Q^{t}$ being the accounting price for $t$, the stock of time. They are defined by $\mathbf{P}:=\left(\partial U / \partial \mathbf{C}^{*}\right) / \Lambda$ and $\mathbf{Q}^{\dagger}:=\Psi^{\dagger} / \Lambda$, where $\Psi^{\dagger}$ is the costate variable of $\mathbf{K}^{\dagger}$, and the extended price index $\Lambda(t)$ is s.t. $\dot{\mathbf{P}}(t) \cdot \mathbf{C}^{*}(t)=0$ for all times $t$.

$\Lambda$ (denoted $\lambda \pi$ in $\mathrm{AW}$ ) is thus defined so that the price vector $\mathbf{P}$ represents real prices, while the real interest rate is $r(t):=\rho-\dot{\Lambda}(t) / \Lambda(t)$.

The key results in AW and PT are:

$$
\begin{aligned}
& \dot{Y}^{\dagger}(t)=r(t) \mathbf{Q}^{\dagger}(t) \cdot \dot{\mathbf{K}}^{* \dagger}(t) \\
& \left\{\dot{Y}^{\dagger}(t) \leq 0 \text { or } r(t) \mathbf{Q}^{\dagger}(t) \cdot \dot{\mathbf{K}}^{* \dagger}(t) \leq 0\right\} \Rightarrow\left\{U(t)>U^{m}(t)\right\}
\end{aligned}
$$

where $U^{m}(t):=\max U$ s.t. $U(\mathbf{C}(s)) \geq U$ for all $s \geq t$, so that the economy is then by definition unsustainable at $t$; and

the value of time, $Q^{t}(t)$

$$
=\int_{t}^{\infty}[\partial Y(s) / \partial s] \exp \left[-\int_{t}^{s} r(z) \mathrm{d} z\right] \mathrm{d} s .
$$

A useful intuition behind result (3) is that in a dynamically efficient economy, augmented GNNP, namely the increase in output, equals the rate of return on augmented GS, namely net additions to the capacity of that economy. From the above results, it is tempting to suggest that the ratios $\dot{Y}^{\dagger} / Y^{\dagger}$ or $r \mathbf{Q}^{\dagger}$. $\dot{\mathbf{K}}^{* \dagger} / Y^{\dagger}$ measure how sustainable an economy is, though note that (4) is a one-sided test of unsustainability. In fact there is still no theory, nor even a precise definition, of an economy's degree of sustainability. Nevertheless, results (3) and (4) do motivate our measurement here of $\dot{Y}^{\dagger}$ and $r \mathbf{Q}^{\dagger} \cdot \mathbf{K}^{* \dagger}$ for Scotland, to explore how valid and therefore useful this theory of (un)sustainability might be in practice. Since factors such as tax distortions and business cycles in any real economy like Scotland will cause it not to maximise present value, it is obviously a considerable approximation to use the above theory, but there is currently little alternative, if governments wish to use macro indicators of sustainability which have at least some grounding in economic theory (Hanley and Atkinson, 2003). The paradox that even if present value was maximised, there would be no obvious motive to investigate sustainability, was noted in PT Section 3.2, and will not be further explored here.

\section{A specific theoretical model of the Scottish economy}

For our empirical estimation, we apply a specific version of the above theoretical model to the Scottish economy with capital and consumption vectors $\mathbf{K}$ and $\mathbf{C}$ which we now describe in detail. All variables are assumed to be endogenous functions of time, unless they are specifically noted as parameters, or are exogenous functions of time denoted by an explicit dependence on $t$.

\subsection{Capital stocks and production}

We model Scotland's capital stocks as $\mathbf{K}:=\left(K, K^{f}, \boldsymbol{S}\right)$. The vector $\boldsymbol{S}:=\left(S^{1}, \ldots, S^{5}\right)$ denotes Scotland's domestic stocks of 5 renewable and non-renewable resources: coal, aggregates (sand and gravel), North Sea oil, ${ }^{1}$ wild (not farmed) fish and commercial forestry. The $i$ th domestic resource stock changes as

$\dot{S}^{i}=D^{i}+G^{i}\left(S^{i}\right)-R^{d i}-R^{X i}+R^{M i}, i=1, \ldots, 5$.

where the contributory flows are discovery $D^{i}$, the stock-dependent natural increase $G^{i}\left(S^{i}\right)$ (non-zero only for fish and forests), domestic use $R^{d i}$, exports $R^{X i}$ and imports $R^{M i}$; together we denote $\boldsymbol{D}:=\left(D^{1}, \ldots, D^{5}\right), \boldsymbol{G}:=\left(G^{1}, \ldots, G^{5}\right)$, etc. For practical estimations, wherever data on the change $\dot{S}^{i}$ of a resource stock are available directly, they are used instead of Eq. (6).

Scalar $K$ is Scotland's stock of domestic manmade physical capital, which grows at the rate of gross investment (Domestic Fixed Capital Formation) $I$ minus depreciation $\delta K$ :

$\dot{K}=I-\delta K$.

Scalar $K^{f}$ is Scotland's stock (debt if $K^{f}<0$ ) of net foreign capital, held privately or by the government, which earns a return at the exogenous, constant world

\footnotetext{
${ }^{1}$ Although the North Sea has both oil and natural gas, only oil was considered for Scotland, since about $80-90 \%$ of the UK's gas stocks can be estimated to lie on the English side of a notional marine border between the two countries.
} 
interest rate $r$. It grows as a result of interest on the capital plus exports $X$ minus imports $M:^{2}$

$\dot{K}^{f}=r K^{f}+X-M$.

Production of a consumption/investment good is $F\left(K, \boldsymbol{R}^{d}, t\right)$, the last dependence being the effect of exogenous technical progress. ${ }^{3}$ Production $F$ plus net imports $M-X-\boldsymbol{Q}^{R} \cdot\left(\boldsymbol{R}^{M}-\boldsymbol{R}^{X}\right)$ of the consumption/investment good (but not resources) given world resource prices $\boldsymbol{Q}^{R}$, is distributed among consumption $C$; gross investment $I$; firms' abatement current expenditure $a$; government spending $J$ on agri-environmental (rural landscape) improvement schemes; firms' resource discovery costs $V(\boldsymbol{D}, \boldsymbol{S})$ with $V_{\boldsymbol{D}}>0$; and firms' extraction costs $f\left(\boldsymbol{R}^{d}+\boldsymbol{R}^{X}-\boldsymbol{R}^{M}, \boldsymbol{S}\right)$ with $f_{\mathbf{1}}>\mathbf{0}, f_{\boldsymbol{S}}<\mathbf{0}$ :

$$
\begin{aligned}
F( & \left.K, \boldsymbol{R}^{d}, t\right)+M-X-\boldsymbol{Q}^{R} \cdot\left(\boldsymbol{R}^{M}-\boldsymbol{R}^{X}\right) \\
= & C+I+a+J+V(\boldsymbol{D}, \boldsymbol{S}) \\
& +f\left(\boldsymbol{R}^{d}+\boldsymbol{R}^{X}-\boldsymbol{R}^{M}, \boldsymbol{S}\right)
\end{aligned}
$$

\subsection{The consumption vector and utility}

Instantaneous utility is $U(\mathbf{C})=U(C, \boldsymbol{E}, B) ; U_{C}$, $U_{B}>0, U_{\boldsymbol{E}}<\mathbf{0}$; where $C$ is material consumption, $\boldsymbol{E}$ is an emissions vector and $B(J)$ is the flow of "added environmental quality", measured in some physical index of improved amenity and biodiversity on agricultural land, that results from a total rate of government spending $J(t)$ on "agri-environmental" schemes. This creates real prices $P^{C}$ for consumption, $P^{E}$ (also a vector) for emissions and $P^{B}$ for agri-environmental quality, which together satisfy the Divisia property in (2) and thus make $P^{C} C+\boldsymbol{P}^{E} \cdot \boldsymbol{E}+P^{B} B$ an index of utility measured in consumption units. Emission flows

\footnotetext{
${ }^{2}$ The world interest rate could of course vary over time. This would result in an extra term $r K^{f}$ in the integrand of $Q^{t}$ in (14) (see PT, Eq. (4.40)).

${ }^{3}$ Note that we ignore any effects of emissions on production $F$ rather than directly on utility $U$. This accords well with the dominant focus on health effects that underlies our empirical estimates of emissions damages reported below in Appendix B. And unlike PT, we have no separate measure of abatement capital, owing to data not being collected on this specific capital stock.
}

$\boldsymbol{E}:=\left(E^{1}, \ldots, E^{6}\right)$ are measured for 6 pollutants: sulphur dioxide $\left(\mathrm{SO}_{2}\right)$, particulate matter less than $10 \mu \mathrm{m}$ in diameter (PM10), carbon monoxide (CO) and three greenhouse pollutants: carbon dioxide $\left(\mathrm{CO}_{2}\right)$, nitrous oxide $\left(\mathrm{N}_{2} \mathrm{O}\right)$ and methane $\left(\mathrm{CH}_{4}\right)$. (Although it is the flows and not the concentrations of greenhouse pollutants that will be measured, the marginal damage cost of each of these takes into account its atmospheric lifetime effect or 'global warming potential'.) Total abatement spending $a$ is notionally divided into separate spending levels $\left\{a^{j}\right\}$ with $a=\sum_{j=1}^{6} a^{j}$, and each emission level $E^{j}\left(\boldsymbol{R}^{d}, a^{j}\right), a$ depends on domestic resource use and abatement expenditure. We denote the marginal cost of abating pollutant $j$ as:

$e^{j}(t):=1 /\left(-\partial E^{j} / \partial a^{j}\right)$, with $\boldsymbol{e}:=\left(e^{1}, \ldots, e^{6}\right)$,

which in an optimal economy will equal $-P^{E j} / P^{C}$, the marginal benefit of abating the pollutant. We likewise denote:

$$
\begin{aligned}
b(t): & =1 / B^{\prime}(J), \text { the marginal cost of improving } \\
& \text { agri }- \text { environmental quality. }
\end{aligned}
$$

In the absence of sufficient data, we assume that all marginal abatement and improvement costs are constant for all pollutants during the period under consideration, even though one might in practice expect them to grow as income per head grows (Hokby and Soderqvist, 2003; Bruvoll et al., 2003). (This would also mean from (2) that the price index $\Lambda$ grows faster as a result of $\boldsymbol{P}^{E}$ and $P^{B}$ being included in an extended price vector.) We show in Appendix A that the "price of consumption" $P^{C}$ (relative to the consumptionplus-environmental-values-aggregate which is dollarised utility) is then constant, and can be set to unity.

\subsection{Income measures and marginal benefit versus cost estimates}

For later use, we define Net National Product $(N N P)$ as:

$\mathrm{NNP}=C+J+\dot{K}+\dot{K}^{f}$.

Note that environmental spending by government (here $J$ on agri-environmental improvement) is thus part of NNP, but environmental and resource spending 
by firms (here $a$ on pollution abatement, $V$ on resource discovery and $f$ on resource extraction) is not. This is because by national accounting conventions, firm (as opposed to governmental or household) expenditures are treated as intermediate, and thus already excluded from all calculations of national product (whether gross or net, domestic or national) in order to avoid double counting. This convention is inconsistently applied in some literature (compare for example its treatment in Hamilton and Atkinson, 1996, pp. 676-677, Hamilton, 1996 and Atkinson et al., 1997), and may be changed for resource discovery costs sometime in the future (see ONS, 1998, Section 11.25), but it did apply for the time period of this study.

All functions are assumed to be as smooth and convex as needed for maximised present value $W\left\{\mathbf{C}^{*}(t)\right\}$ in (3) to converge, and for partial derivatives with respect to control variables $C,\left\{a^{j}\right\}, J, D$, $\boldsymbol{R}^{d}, M-X$ and $\boldsymbol{R}^{X}-\boldsymbol{R}^{M}$ (denoted by subscripts below) to exist. Appendix A then shows that:

Augmented GNNP : $Y^{\dagger}=C-\boldsymbol{e} \cdot \boldsymbol{E}+b B+\dot{K}+\dot{K}^{f}$

$$
+\left(\boldsymbol{Q}^{R}-f_{\boldsymbol{R}}\right) \cdot \dot{\boldsymbol{S}}+Q^{t}
$$

Value of time :

$Q^{t}(t)=\int_{t}^{\infty}\left[F_{s}+\dot{\boldsymbol{Q}}^{R} \cdot\left(\boldsymbol{R}^{X}-\boldsymbol{R}^{M}\right)\right](s) \boldsymbol{e}^{-r(s-t)} d s ;$ and

Augmented GS :

$\mathbf{Q}^{\dagger} \cdot \dot{\mathbf{K}}^{\dagger}=\dot{K}+\dot{K}^{f}+\left(\boldsymbol{Q}^{R}-f_{\boldsymbol{R}}\right) \cdot \dot{\boldsymbol{S}}+Q^{t}$.

So if predictions, or at least scenarios, are made for future exogenous technical change $\partial F / \partial t\left(F_{S}\right.$ in (14)), resource price changes $\dot{\boldsymbol{Q}}^{R}$, and net resource exports $\left(\boldsymbol{R}^{X}-\boldsymbol{R}^{M}\right)$, then (14) gives the value of time.

We can then use (12) to derive alternative expressions for (13) and (15) which start from NNP data, and thus avoid the need for finding data on net investments $\dot{K}$ and $\dot{K}^{f}$ when calculating augmented GNNP and GS:

Augmented GNNP : $Y^{\dagger}=\mathrm{NNP}-\boldsymbol{e} \cdot \boldsymbol{E}+b B-J$

$$
+\left(\boldsymbol{Q}^{R}-f_{\boldsymbol{R}}\right) \cdot \dot{\boldsymbol{S}}+Q^{t}
$$

Augmented GS :

$$
\begin{gathered}
\mathbf{Q}^{\dagger} \cdot \dot{\mathbf{K}}^{\dagger}=Y^{\dagger}-\boldsymbol{P} \cdot \boldsymbol{C}=Y^{\dagger}-(C-\boldsymbol{e} \cdot \boldsymbol{E}+b B) \\
=\mathrm{NNP}-C-J+\left(\boldsymbol{Q}^{R}-f_{\boldsymbol{R}}\right) \cdot \dot{\boldsymbol{S}}+Q^{t} .
\end{gathered}
$$

Eq. (16) shows the "top-down" adjustments necessary to reach augmented GNNP when starting from NNP:

- deduct $\boldsymbol{e} \cdot \boldsymbol{E}$, the (dis-)amenity costs of emissions; - add the net benefit $(b B-J)$ of agri-environmental schemes (which would be zero if we assumed optimal expenditure, and $B=\alpha J$ for some constant $\alpha$ );

- deduct the value $\left(\boldsymbol{Q}^{R}-f_{\boldsymbol{R}}\right) \cdot(-\dot{\boldsymbol{S}})$ of rents from resource stock depletion;

- add the value of time $Q^{t}$.

Finally, we see a possible need for a convention on choosing between estimates of the marginal benefits and the marginal costs of abatement. In real, imperfect economies, the marginal benefit of environmental improvement $\left(P^{B} / P^{C}\right.$ or $-P^{E j} / P^{C}$, where the latter is also known as the marginal damage cost (MDC) of pollution) is often well above the marginal cost of improvement, $b$ or $e^{j}$. (The exception is when an emissions standard is too strict, causing marginal benefit to be below marginal cost.) As Hartwick (1990, p. 296) wrote about externalities caused by open access to renewable resources, "the national accountant faces a no-win choice at this point" between the two marginal values. Hamilton (1996, pp. 29-30) recognised something similar. Peskin and Delos Angeles (2001, p. 211) recommended using marginal benefits rather than marginal costs of environmental improvement because they thought the former easier to calculate, but we find this doubtful as a general rule. The ideal solution is to use accounting prices as in Dasgupta (2001); but given the difficulties of calculating these, we tentatively suggest (and have used) the following, practical convention:

(i) if there are data on only marginal benefits or marginal costs of environmental improvement, use whichever is available;

(ii) if there are data on both benefits and costs, but of very different reliability, use the generally more reliable data; 
(iii) if there are data on both marginal benefits and costs, of broadly similar reliability, use the bigger figure. This will be the marginal benefit if, as one often expects, pollution is excessive;

(iv) be explicit about what choices were made and why, and about how much difference they make to the final results.

In our case, using marginal benefit $\left(-P^{E j} / P^{C}\right)$ rather than marginal cost $\left(e^{j}\right)$ data for abatement follows principle (i) or (ii), depending on the pollutant. For agri-environmental expenditure, we use marginal benefits $\left(P^{B} / P^{C}\right)$ simply to keep the expenditure visible as a separate item in augmented GNNP.

\section{Data sources used for Scotland}

Data were obtained for 1992 to 1999 inclusive from many sources. Input-output (I/O) tables for Scotland were used as the basis for calculating GDP and emission levels. These tables come from a related research project, not otherwise reported here, to construct a computable general equilibrium, economy-environment model of Scotland (see Hanley et al., 2004). Calculations of natural resource rents do not use the I/O tables, but are based on estimates of Scottish natural resource stocks obtained directly from primary sources. Because Scotland is mainly a regional, not national economy, pro-rata approximations based on UK totals often had to be used for other data, as in Hanley et al. (1999).

\subsection{GDP, GNP, NNP, capital depreciation and the interest rate}

GDP data, measuring the value of total income and the value of total output (production), were available from the I/O tables for the Scottish economy, but GNP data were not. To estimate GNP data, we first converted a nominal GDP series taken from the Scottish Executive, checked against annual I/O tables, and converted it into real 1999 prices using HM Treasury's GDP deflator for the UK. For each year, we then used the ratio of UK GDP to
GNP to further convert the Scottish GDP figures to GNP:

$\mathrm{GNP}(\mathrm{Scot}) \approx[\mathrm{GNP}(\mathrm{UK}) / \mathrm{GDP}(\mathrm{UK})] \times \mathrm{GDP}(\mathrm{Scot})$

GNP data for Scotland were further converted to NNP by deducting estimates of man-made capital depreciation. Since no data exist on the element of depreciation in Scotland, the estimates came from multiplying the UK depreciation ratio $(\delta K / I)$ by a series for Gross Domestic Fixed Capital Formation for Scotland obtained from the I/O tables. This procedure also readily yielded estimates of net investment $(\dot{K})$ :

$\mathrm{NNP}(\mathrm{Scot})=\mathrm{GNP}(\mathrm{Scot})-\delta K(\mathrm{Scot})$, and

$\dot{K}(\mathrm{Scot})=I(\mathrm{~S} \operatorname{tot})-\delta K(\mathrm{~S} \cot )$, where

$\delta K(\mathrm{Scot}) \approx[\delta K(\mathrm{UK}) / I(\mathrm{UK})] \times I(\mathrm{Scot})$.

Eq. (19) was used in (16) to calculate augmented GNNP from NNP, while (20) was used in (15), along with estimates of $\dot{K}^{f}$ taken from Gibson et al. (1997), to calculate augmented GS.

Two alternative real interest rates $(r)$ of $2 \% /$ year and $6 \% /$ year were used. The $2 \% /$ year is an estimate of the UK's real consumption discount rate, from values in Pearce (2003) that were derived, using the Ramsey rule, from the pure time preference rate, long term real growth rates in the UK economy, and the elasticity of the marginal utility of consumption. $6 \% /$ year was the UK Treasury's discount rate during 1992-1999 for public sector investments (HM Treasury, 1997).

\subsection{Polluting emissions and agri-environmental spending}

To calculate polluting emissions, the Scottish economy was divided into 76 sectors and the pollution attributable to each sector was estimated. We used emission/output ratios for the UK, but then further adjusted estimated Scottish emissions, using the ratio of economic activity for each sector between Scotland and the UK (Turner, 2003). This assumes pollution per unit output is the same between Scotland and the UK for any given sector. 
This is often not the case: for example, electricity production uses less polluting technologies (proportionately more hydro-electricity) in Scotland. However, no data exist on Scottish-specific emission coefficients for each sector of the economy.

The marginal damage costs (MDCs, i.e. the marginal benefits of abatement) of pollutants were taken from a literature review (see Appendix B). Wherever possible, estimates based on the UK were used, and the studies chosen were those considered to be statistically valid by the EU Environment Directorate. As more than one study existed for all pollutants, an average of the results was used. As noted in Section 3.2 , the impacts included in the studies are mainly those on health. No real change in MDCs over time was estimated, owing to insufficient data.

There are several agri-environmental schemes in Scotland, and the Scottish Executive Environment and Rural Affairs Department gave details of the cost and the area of take-up for each scheme. Schemes included were Environmentally Sensitive Areas, Habitat Scheme, Heather Moorland Scheme, Organic Aid Scheme and the Countryside Protection Scheme. Our money value for the benefits of each hectare came from studies of two Scottish Environmentally Sensitive Areas in Hanley et al. (1998).

\subsection{Natural resource depletion and growth}

For both coal and aggregates, production data were taken from the UK Minerals Yearbook (various years). The ex-works value of UK production was divided by the quantity produced giving a unit value for UK production, which was multiplied by the Scottish production to give Scottish value. The British Geological Survey, authors of the yearbook, suggested that this exworks value be used as a proxy for price data. Marginal cost data for coal were provided by Scottish Coal. This assumes a constant ratio of values between the UK and Scotland, so that differences in the proportions of open cast and deep mined coal, or marine- and land-sourced aggregates, cannot be included. Also sand and gravel are the only aggregates included, which may ignore some other aggregates included in the $\mathrm{I} / \mathrm{O}$ tables.

Fisheries data were obtained from the UK Department for Environment, Food and Rural Affairs (DEFRA). There is no such legal entity as "Scottish fish stock", so we chose stocks in fishing areas around the Scottish coastline as representing "Scottish fish"; and the way that the data are presented by DEFRA means that for certain fish species it was necessary to include some of the English Channel in the data. The values of the fish stocks were taken from the same data source. Nautilus Consulting suggested the marginal cost of fishing be represented by fuel and oil costs $(17.5 \%$ of value).

For forestry, the Forestry Commission provided stock figures, prices and marginal costs. Marginal costs were based on an estimated cost of moving $\log _{s}$ from the site of felling to the roadside and were assumed to be constant throughout the period.

Data for Scotland's oil stocks and world oil prices (historical and future predictions) were gained from the Energy Information Administration, a branch of the US Department of Environment. These data includes increases in stocks in some years due to technological advances, and new discoveries. Marginal extraction cost data were derived from discussions with individuals in the oil industry. A value of $\$ 3.5 /$ barrel was chosen based on costs in the Alba oilfield, being the operational expenditure of a major oil company, adjusted as oil from Alba trades at a discount to much North Sea oil. However, these data are not historical and so did not allow us to estimate any changes to the marginal costs.

\subsection{The value of time (from technical progress and oil price changes)}

The value of time, $Q^{t}$ in (14), comprises the net present value over an infinite time horizon of two terms: $F_{t}$, exogenous technical change in production, and $\dot{\boldsymbol{Q}}^{R} \cdot\left(\boldsymbol{R}^{X}-\boldsymbol{R}^{M}\right)$, the value of exogenous resource price changes, weighted by net exports. For our calculations, we truncated the time horizon to 20 years, because forecasts for either term beyond then are very dubious. We have used estimates of total factor productivity (TFP) (i.e. GDP growth not accounted for by increased use of capital and labour) from Senhadji (2000) and Crafts and O'Mahony (2001) for the UK, to estimate the Scottish TFP growth rate for 1992-1999, and have used this as our estimate of $F_{t} / F$ to project forward till 2020 . This will obviously include both exogenous and endogenous technical progress, but we were not able to distinguish between them for Scotland. We included only one resource 
price change, that for North Sea Oil, and used British Geological Survey data on past imports and exports of crude petroleum from the UK. Actual data (up to 2001) and price predictions (2001 onwards) were used to calculate changes in price, using the Energy Information Administration predictions noted in Section 4.3, since it seemed desirable to use actual data where possible. The UK as a whole has net exports of about $5 \mathrm{~m}$ barrels/year of crude petroleum. It was assumed that with $10 \%$ of the UK's population, Scotland would export $90 \%$ of the remaining production to the rest of the UK. The average of exports in the years 1994-2000 was considered to be a valid estimate of future oil exports from Scotland.

\section{Results}

\subsection{Main results}

These are in Table 1. The first part shows annual results for 1992-1999 for some constituent parts of green NNP, starting with conventional GNP and ending with the value of time; for augmented GNNP and augmented GS; and then for the change in augmented GNNP, and the interest on augmented GS. The change in augmented GNNP from 1992 to 1993 is shown under 1993 and likewise for later years, so there is no data point for 1992. Augmented GNNP is about $7-2 \%$ less than NNP, with the gap falling steadily over 1992-1999. So the green and augmentation terms do not make a big difference to the results, which reduces the need for the various sensitivity analyses which clearly could be undertaken of any of the above assumptions behind these terms; and augmented GNNP actually grows faster than NNP. Fig. 1 plots the augmented GNNP and augmented GS results, and shows clearly how augmented GNNP is always rising and augmented GS is always positive, suggesting no evidence from either indicator of unsustainable development in Scotland during 1992-1999, according to the theory. The positive values of augmented GS are largely thanks to net investment in man-made capital $(\dot{\mathbf{K}}$ in $(15))$ being positive and many times bigger than the aggregate depletion of natural resources $\left(-\left(\boldsymbol{Q}^{R}-f_{\boldsymbol{R}}\right) \cdot \dot{\boldsymbol{S}}\right.$ in (15)) that we have been able to measure.

These results are in contrast to results for roughly similar measures found in Figs. 1 and 2 of Hanley et al. (1999) for 1980-1993. There, Approximate Envi-

Table 1

Totals and constituent parts of change in augmented GNNP and interest on augmented GS for Scotland, 1992-1997

\begin{tabular}{|c|c|c|c|c|c|c|c|c|}
\hline & 1992 & 1993 & 1994 & 1995 & 1996 & 1997 & 1998 & 1999 \\
\hline \multicolumn{9}{|l|}{ Main calculation using $2 \%$ real interest rate } \\
\hline Conventional GNP & 47946 & 48982 & 51685 & 54221 & 54592 & 54637 & 56533 & 56897 \\
\hline$\delta K$ (depreciation of man-made capital) & 8340 & 9301 & 9460 & 8385 & 7568 & 7496 & 6934 & 6863 \\
\hline $\mathrm{NNP}=\mathrm{GNP}-\delta K$ & 39606 & 39680 & 42225 & 45836 & 47024 & 47140 & 49599 & 50034 \\
\hline $\boldsymbol{e} \cdot \boldsymbol{E}=$ pollution damage & 3096 & 2906 & 2615 & 2444 & 2290 & 2097 & 2108 & 1712 \\
\hline$b B-J=$ net benefit of agri-environmental schemes & 1 & 1 & 2 & 3 & 3 & 2 & 4 & 4 \\
\hline$\left(\boldsymbol{Q}^{R}-f_{\boldsymbol{R}}\right) \cdot \dot{\boldsymbol{S}}=$ negative resource rents & -293 & -184 & -87 & -233 & -199 & -164 & -81 & 109 \\
\hline$Q_{t}=$ value of time & 716 & 682 & 690 & 609 & 609 & 621 & 675 & 752 \\
\hline Augmented GNNP $=\mathrm{NNP}-\boldsymbol{e} \cdot \boldsymbol{E}+b B-J+\left(\boldsymbol{Q}^{R}-f_{\boldsymbol{R}}\right) \cdot \dot{\boldsymbol{S}}+Q^{t}$ & 36934 & 37273 & 40214 & 43771 & 45146 & 45502 & 48089 & 49186 \\
\hline Augmented GNNP/NNP & $93 \%$ & $94 \%$ & $95 \%$ & $95 \%$ & $96 \%$ & $97 \%$ & $97 \%$ & $98 \%$ \\
\hline Augmented genuine savings (GS) & 1943 & 1651 & 2155 & 2507 & 2492 & 2791 & 3625 & 3664 \\
\hline Change in augmented GNNP & - & 339 & 2942 & 3557 & 1375 & 356 & 2587 & 1098 \\
\hline Interest rate $r \times$ augmented GS & 39 & 33 & 43 & 50 & 50 & 56 & 73 & 73 \\
\hline \multicolumn{9}{|c|}{ Sensitivity testing by using $6 \%$ real interest rate; then adding educational expenditure } \\
\hline$Q^{t}=$ value of time & 519 & 488 & 498 & 419 & 418 & 429 & 482 & 561 \\
\hline Change in augmented GNNP & - & 342 & 2944 & 3559 & 1374 & 355 & 2586 & 1099 \\
\hline Interest rate $r \times$ augmented GS & 105 & 87 & 118 & 139 & 138 & 156 & 206 & 208 \\
\hline Estimated educational expenditure & 2579 & 2646 & 2776 & 2899 & 2908 & 2903 & 2991 & 3010 \\
\hline Interest rate $r \times$ augmented GS including educational expenditure & 259 & 246 & 284 & 313 & 313 & 330 & 385 & 389 \\
\hline
\end{tabular}

All values except \% are £ million in constant 1999 prices. 


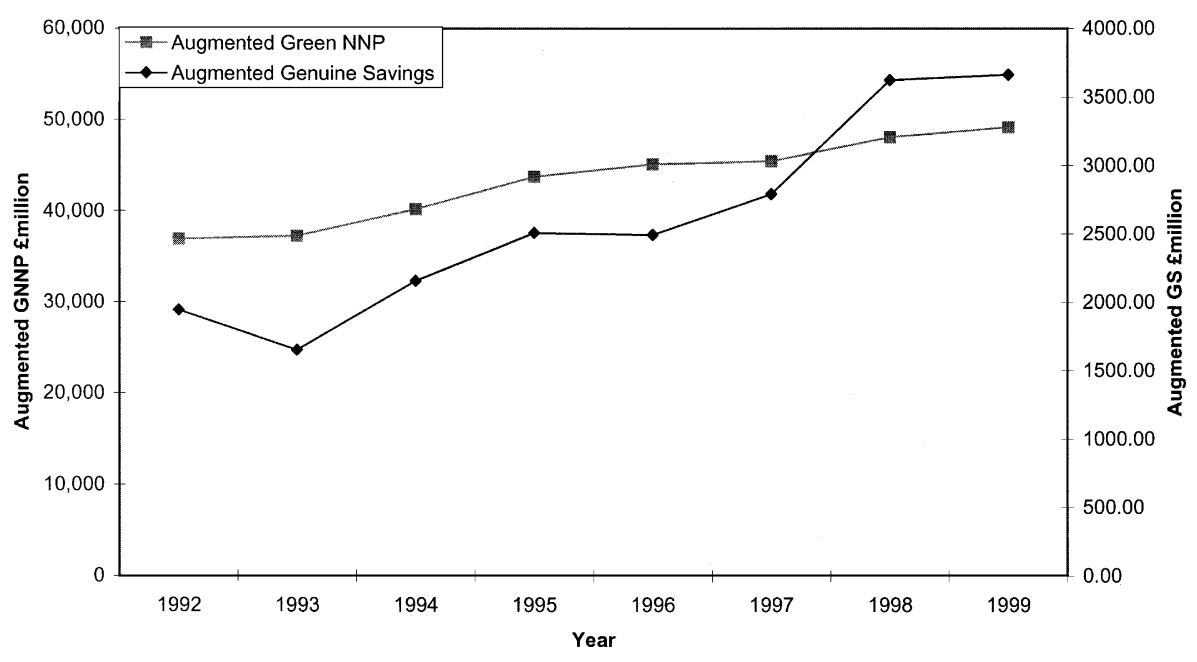

Fig. 1. Augmented green NNP and augmented genuine savings for Scotland.

ronmentally-Adjusted National Product (excluding oil discoveries) mainly rose, though not every year; but GS (also excluding discoveries) was always negative. These contrasts can be ascribed mainly to the very different real conditions in the 1980s, when oil was both more expensive and being depleted more rapidly in Scotland; and also to differences in how the various measures have been defined and calculated. Macroeconomic conditions were also rather different in the 1990 s compared with the 1980 s, a point we explain further below.

Considering the green terms in our results, including some data not shown in Table 1, yields the following observations. Natural capital is indeed depleted (that is, aggregate resource rents $\left(\boldsymbol{Q}^{R}-f_{\boldsymbol{R}}\right) \cdot(-$ $\dot{\boldsymbol{S}})$ are positive) in all but the last year, although forestry stocks are in fact rising throughout. Fish stocks rise in some periods and fall in others; oil production exceeds new discoveries in a few years. Coal and aggregates are always depleted in net terms since we do not count new discoveries for these. Total damage costs of all six pollutants fall over the period from about $8 \%$ to about $3 \%$ of augmented GNNP, because emissions fall; and $\mathrm{SO}_{2}$ causes the most damage, followed by PM10. Agri-environmental schemes give positive net benefits in all years, but are tiny in relation to other elements of augmented GNNP, in line with our observation above that net benefits could optimally be zero.
The value of time $Q^{t}$ is always positive. The largest element of $Q^{t}$ is the future growth in production possibilities through technical progress $F_{t}$, with a much smaller part due to future oil price rises $\dot{\boldsymbol{Q}}^{R}$ into the future (the other term in (14)). For example, in 1998 the discounted integral of $F_{t}$ is $86 \%$ of the total value of $Q^{t}$, a result of course specific to this study, and not general.

However, by far the most striking observation is what we will call the mismatch problem, shown by the last two rows of the first part of Table 1:

The change in augmented GNNP is for all years much bigger (but by a very variable ratio, between about 6 and 70) than the interest on augmented GS, instead of roughly matching it as predicted by equation [8] from AW's theory.

Fig. 2 graphs these two data series, but using right and left scales which differ by a factor of 50 .

This rejection of the underlying optimal growth theory is the major, though unexpected result, of our paper. We have some initial ideas, explained below, about the nature of utility functions assumed that may prove fruitful to investigate in trying to explain the mismatch problem, but such investigations remain for further work. Meanwhile we first check how robust the mismatch problem is, using various sensitivity tests reported in the second part of Table 1. 


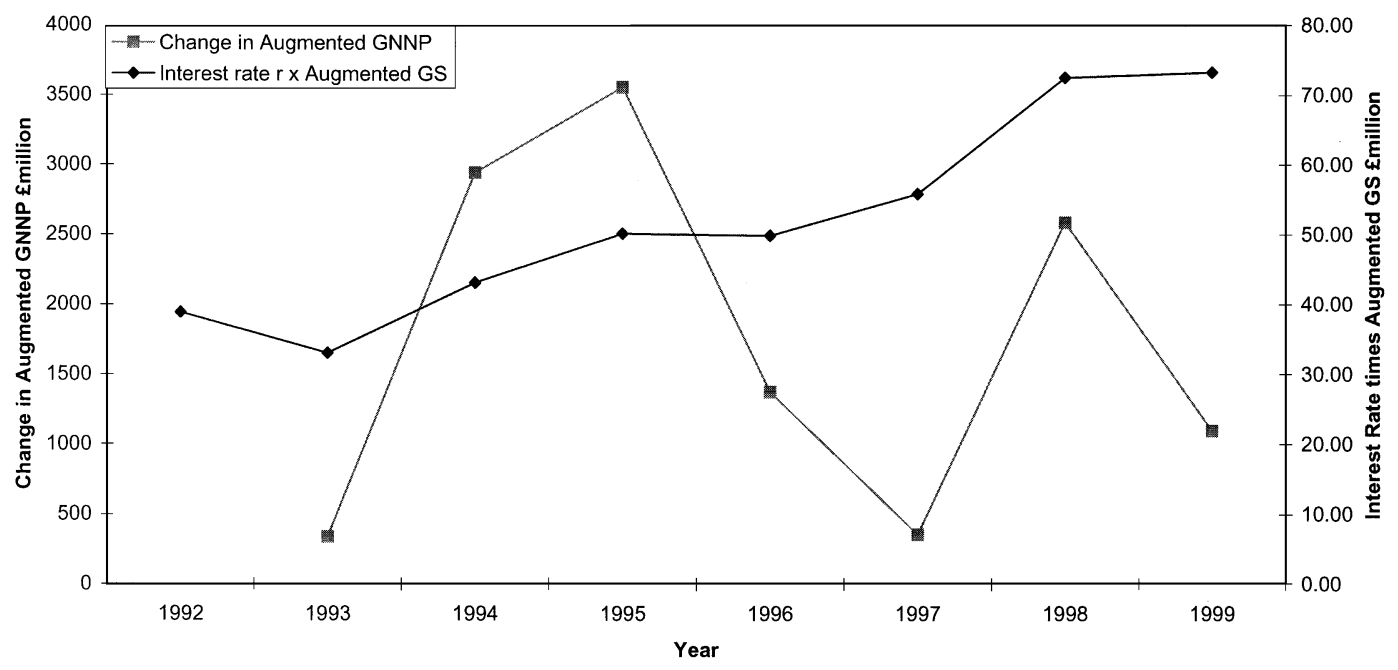

Fig. 2. Change in augmented green NNP and interest on augmented genuine savings for Scotland.

5.2. Sensitivity tests and business cycles: can we explain the mismatch problem?

Whatever the mismatch problem is, it is unlikely to be caused by green or augmentation adjustments to national accounts, since as already observed, such adjustments never exceed $7 \%$ of conventional NNP here. Nevertheless, the first test of our results was to examine how sensitive they are to variations in the marginal damage costs of pollutants. We calculated augmented GNNP with the lowest or highest MDC values considered to be defensible, instead of the midrange values chosen for the above calculations. The costs of pollution damage with the low values were about $30-35 \%$ lower than with the mid-range values, and about $20-25 \%$ higher with the high values. But because of the low overall weight of the pollution damage costs, as shown in Table 1, in no case was the difference between low-MDC and high-MDC values of augmented GNNP more than 5\%; while the differences in the changes in augmented GNNP, which is naturally more volatile, were less than $25 \%$. On this evidence, the precise choice of pollution damage costs is not crucially important when estimating sustainability measures for an industrialised nation, and we do not report results for the test in Table 1.

The second test examines two choices of interest rate, $2 \%$ for the estimated UK real consumption discount rate, and $6 \%$ for the test rate of discount for UK public sector projects during 1992-1999, already noted in Section 4.1. The results for both rates are in Table 1. The effect of the interest rate alone can be seen comparing the lower and middle graphs on Fig. 3 . The higher discounting of future changes reduces the value of time $Q^{t}$ by about $30 \%,{ }^{4}$ so augmented GS is lower, but this reduction is greatly outweighed by the tripling of the interest rate when calculating the interest on augmented GS. (Augmented GNNP is barely changed, so no results are given).

The third sensitivity test, which also increases the interest on augmented GS relative to the change in augmented GNNP, is to follow Hamilton and Clemens (1999, p. 346). They argued that current, ultimately arbitrary conventions in national accounting practice treat the vast majority of educational expenditure as consumption, which is better reclassified as investment in human capital. Doing this in our theoretical model is so simple that a formal treatment is unnecessary (though a more thorough treatment would allow for capital depreciation through people retiring, and thus be more complex). Reclassifying items from consumption to investment increases augmented GS (part of the total in (1)), but leaves augmented GNNP (the total) unchanged. We have no exact data on

\footnotetext{
${ }^{4}$ It also makes the truncation of the $Q^{t}$ integral at 20 years more justifiable, since $(1 / 1.06)^{20}=0.312$, whereas $(1 / 1.02)^{20}=0.673$.
} 


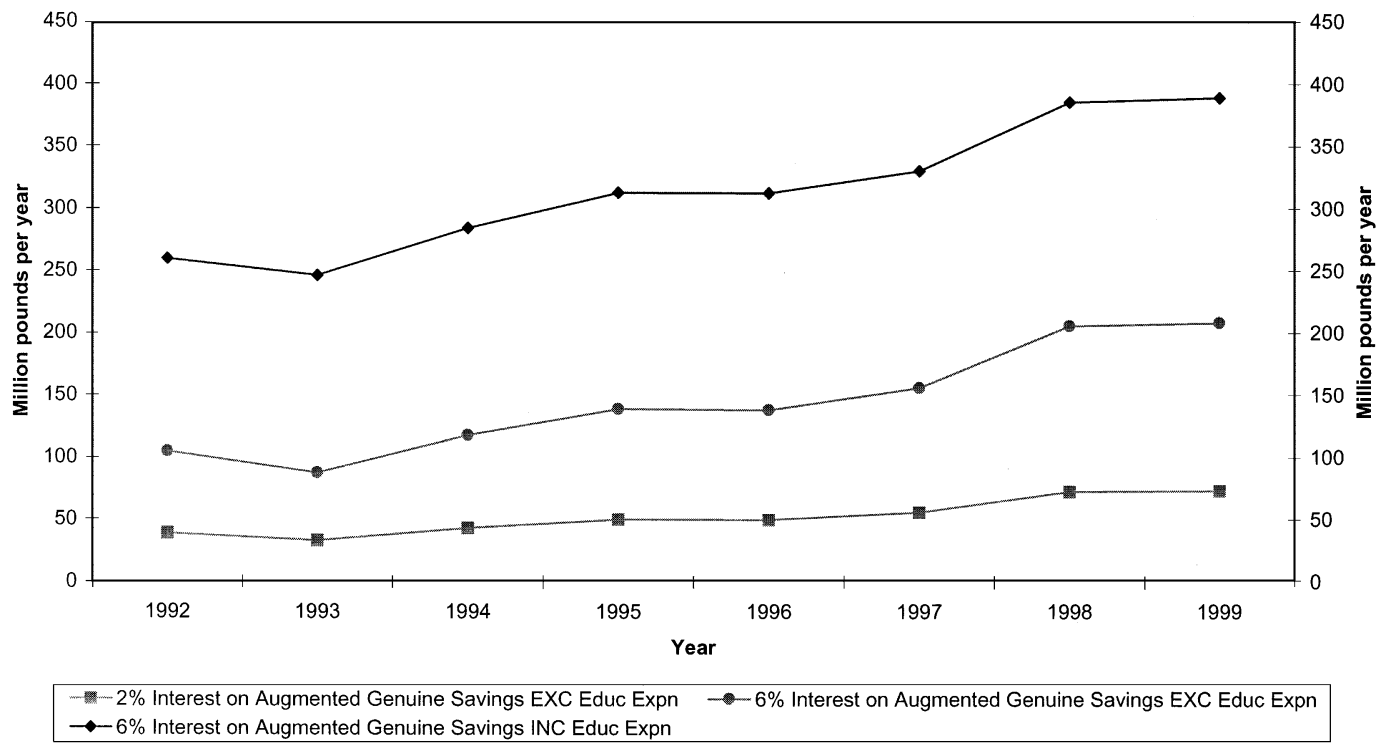

Fig. 3. Sensitivity tests on interest on augmented genuine savings for Scotland.

Scottish educational expenditure, so as before we apply the UK ratio (here $4.7 \%$ ) to Scottish GDP, to produce the figures in the penultimate line of Table 1. These are the same order of magnitude as our previous augmented GS, so the effect is roughly to double our estimate of $6 \%$ interest on augmented GS, from the middle to the upper graph in Fig. 3. However, comparing the last with the second data line of the second part of Table 1 shows that the interest on augmented GS still remains at about a fifth of the mean change in augmented GNNP over the period.

Another partial explanation for the mismatch problem, for which we thank a referee, may lie outside the theory used above. As noted, the theory assumes full capacity utilisation at all times and thus excludes business cycles. But there was a recession in the UK in the early 1990s, so that Scottish capacity utilisation was surely higher in 1999 than in 1992. Estimating degrees of utilisation is tricky, since it involves counterfactuals (e.g. what would output have been given full utilisation?), but our best estimate is that Scotland's degree of utilisation, say $Z(t)$ (actual output divided by potential output) increased by no more than $0.2 \% /$ year during 1992-1999. How much of the mismatch problem could this explain?

If we denote actual rather than full-capacity variables by a subscript a, so that actual augmented
GNNP is $Y_{a}^{\dagger}=Z Y^{\dagger}$, assume that result (3) still applies approximately to full-capacity $Y^{\dagger}$, and use GS to mean augmented genuine savings, then (3) becomes $\dot{Y}_{a}^{\dagger} \approx(\dot{Z} / Z) Y_{a}^{\dagger}+r \mathrm{GS}_{a}\left(\mathrm{GS} / \mathrm{GS}_{a}\right)\left(Y_{a}^{\dagger} / Y^{\dagger}\right) \approx 0.002 Y_{a}^{\dagger}+$ $r \mathrm{GS}_{a}$. The implication is that a fairer empirical test of our theory is to compare $\dot{Y}_{a}^{\dagger}$ with $0.002 Y_{a}^{\dagger}+r \mathrm{GS}_{a}$, rather than just $r \mathrm{GS}_{a}$ as we do in Table 1. However, from Table 1, 0.002 times augmented GNNP never exceeds $£ 100 \mathrm{~m}$, so adding this term makes little difference to the average gap between $r \mathrm{GS}_{a}$, which averages $£ 315 \mathrm{~m}$ during $1992-1999$, and $\dot{Y}_{a}^{\dagger}$, the change in actual augmented GNNP, which averages over $£ 2000 \mathrm{~m}$. Nevertheless, the term is sizeable compared to $r \mathrm{GS}_{a}$, so it is well worth including business cycles in any further empirical tests of AW's results which this paper may trigger.

Our overall judgment is that despite the wellknown practical difficulties of valuing environmental resources, the particular problems of missing data series for a regional economy like Scotland, and the problems of business cycles for any economy, the mismatch between the two measures of sustainability remains so great that it may call into question some of the more basic assumptions of optimal growth theory. It could well be found for many other countries and time periods, using just mainstream (not green or augmented) terms, and it certainly deserves further investigation. 


\section{Conclusions}

We have computed the weak sustainability - strictly speaking, two measures of weak unsustainability - of the Scottish economy during 1992-1999, in a way that reflects recent developments in the relevant economic theory. Our main contribution is twofold. For the first time in a real economy, we have simultaneously included the effects of both technical progress and exogenous changes in trade prices (for oil, in this case) in "augmenting" measures of unsustainability. Also for the first time with real data, we have compared two measures which equal each other in a theoretically perfect, present-value-maximising economy (Asheim and Weitzman, 2001; Pezzey and Toman, 2002): the time change in real, augmented green net national product (GNNP), and the real interest on augmented genuine savings (GS).

To the extent that our data are reliable, our results are clear yet intriguing. Both the change in augmented GNNP and the interest on augmented GS are clearly positive during the period in question, thus giving, by Pezzey and Toman's (2002) one-sided tests, no evidence that the Scottish economy was unsustainable then. They are intriguing in that we calculate the change in augmented GNNP to be always many times bigger than the interest on augmented GS, rather than roughly matching it as theoretically should happen. This mismatch problem is very little affected by any green or augmentation adjustments to our results. And it remains (with a fivefold difference on average) even after making three adjustments which boost the relative size of the interest on augmented GS - using a higher interest rate (the return on investment rather than the consumption discount rate), reclassifying educational expenditure as investment rather than consumption, and making an ad hoc allowance for the Scottish business cycle during 1992-1999. Further work could be done on all three adjustments, for example by including the effect of retirement on net human capital formation, or by reclassifying some parts of health spending as investment, and our estimate of changing capacity utilisation during the business cycle might be improved. But our guess is that the mismatch problem is robust and would still remain. How then might it be explained?

There could be many reasons, but our suggestion is that part of the answer could lie in a misspecified utility function. There is now a wealth of empirical evidence from economists and psychologists that people's happiness depends at least as much on relative consumption - both relative to other people's current consumption, i.e. a perceived status effect, and relative to their own past consumption, i.e. a desire for improvement - as on absolute consumption. (See Brekke and Howarth, 2002 for a detailed exploration of the perceived status effect, and Section 5 of Pezzey, 1997 for a brief review of the desire for improvement.) On that basis the simple utility function $U(\mathbf{C})$ used in our Section 2 theory, which assumes that happiness depends only on absolute (extended) consumption, is substantially misspecified; and we suggest this could be a sizeable cause of our mismatch problem. However, replacing $U(\mathbf{C})$ by something including measures of relative consumption upheaves the theory. Pioneering studies by Howarth (1996) and Brekke and Howarth (2002) showed in simple cases how correcting the externalities caused by status effects can dramatically reduce optimal growth rates compared to actual rates; but our initial explorations of introducing status effects into this paper's theory rapidly became complex. So a full investigation remains for further work, which we believe will be important in assessing the validity of several results on economic growth.

\section{Acknowledgments}

We thank an anonymous referee, Robert Cairns, Quentin Grafton, Peter McGregor, Kim Swales, Martin Weale and seminar participants at the 2003 AARES conference in Fremantle, Western Australia and the 2003 EAERE conference in Bilbao, Spain, for helpful comments. We thank the Economic and Social Research Council for funding the empirical work on which this paper is based. The usual disclaimer applies.

\section{Appendix A. Proof of GNNP and GS formulae}

The current value Hamiltonian of the dynamic optimisation problem of maximising wealth is

$Y^{\dagger}(t):=Y(t)+Q^{t}=\mathbf{P} \cdot \mathbf{C}+\mathbf{Q}^{\dagger} \cdot \dot{\mathbf{K}}^{\dagger}$, where 
$\mathbf{K}^{\dagger}:=\left(K, K^{f}, S, t\right)$ is the vector of all state variables;

$\mathbf{Q}^{\dagger}:=\left(Q^{K}, Q^{f}, Q^{S}, Q^{t}\right)$ is the vector of corresponding co-state variables (shadow consumption prices of stocks).

The prices and investment flows defined by (6)-(11) then make

$$
\begin{aligned}
Y^{\dagger}(t)= & P^{C} C+\sum_{j} P^{E j} E^{j}+P^{B} B+Q^{K} \dot{K} \\
& +Q^{f} \dot{K}^{f}+Q^{S} \cdot \dot{\boldsymbol{S}}+Q^{t}, \text { hence } \\
Y^{\dagger}(t)= & P^{C} C+\sum_{j} P^{E j} E^{j}\left(\boldsymbol{R}^{d}, a^{j}\right)+P^{B} B(J) \\
& +Q^{K}\left[F\left(K, \boldsymbol{R}^{d}, t\right)+M-X-\boldsymbol{Q}^{R}(t)\right. \\
& \cdot\left(\boldsymbol{R}^{M}-\boldsymbol{R}^{X}\right)-C-a-J-V(\boldsymbol{D}, \boldsymbol{S}) \\
& \left.-f\left(\boldsymbol{R}^{d}+\boldsymbol{R}^{X}-\boldsymbol{R}^{M}, \boldsymbol{S}\right)-\delta K\right]+Q^{f} \\
& \times\left[r K^{f}+X-M\right]+Q^{S} \cdot[\boldsymbol{D}+\boldsymbol{G}(\boldsymbol{S}) \\
& \left.-\boldsymbol{R}^{d}-\boldsymbol{R}^{X}+\boldsymbol{R}^{M}\right]+Q^{t}
\end{aligned}
$$

so the first order conditions with respect to the control variables $C, a^{j}, J, \boldsymbol{D}, \boldsymbol{R}^{d}, M-X$ and $\boldsymbol{R}^{X}-\boldsymbol{R}^{M}$ are: $\partial Y^{\dagger} / \partial C=P^{C}-Q^{K}=0 \Rightarrow Q^{K}=P^{C}$

$$
\begin{aligned}
\partial Y^{\dagger} / \partial a^{j} & =P^{E j}\left(\partial E^{j} / \partial a^{j}\right)-Q^{K}=0 \\
& =0 \Rightarrow(\operatorname{using}(10)) P^{E j}=-e^{j} P^{C}
\end{aligned}
$$

$\partial Y^{\dagger} / \partial J=P^{B} B^{\prime}-Q^{K}=0 \Rightarrow(\operatorname{using}(11)) P^{B}=P^{C} b$

$$
\partial Y^{\dagger} / \partial \boldsymbol{D}=-Q^{K} V_{\boldsymbol{D}}+Q^{\boldsymbol{S}}=\mathbf{0} \Rightarrow Q^{\boldsymbol{S}} / Q^{K}=V_{\boldsymbol{D}}
$$

$\partial Y^{\dagger} / \partial \boldsymbol{R}^{d}=\sum_{j} P^{E j} E_{\boldsymbol{R}}^{j}+Q^{K}\left(F_{\boldsymbol{R}}-f_{\boldsymbol{R}}\right)-Q^{\boldsymbol{S}}=\mathbf{0}$

which using (A6) and (A8)

$$
\begin{aligned}
& \Rightarrow-\sum_{j} e^{j} P^{C} E_{\boldsymbol{R}}^{j} / Q^{K}+F_{\boldsymbol{R}}-f_{\boldsymbol{R}}=Q^{S} / Q^{K} \\
& \Rightarrow-\sum_{j} e^{j} E_{\boldsymbol{R}}^{j}+F_{\boldsymbol{R}}=V_{\boldsymbol{D}}+f_{\boldsymbol{R}}
\end{aligned}
$$

$$
\partial Y^{\dagger} / \partial(M-X)=Q^{K}-Q^{f}=0 \Rightarrow Q^{f}=Q^{K}=P^{C}
$$

$\partial Y^{\dagger} / \partial\left(\boldsymbol{R}^{X}-\boldsymbol{R}^{M}\right)=Q^{K}\left(\boldsymbol{Q}^{R}-f_{\boldsymbol{R}}\right)-Q^{\boldsymbol{S}}=0 ; \quad$ then use (A10), (A8):

$$
Q^{S} / Q^{K}=Q^{R}-f_{\boldsymbol{R}}=V_{\boldsymbol{D}}
$$

Inserting (10) and (A6)-(A11) into (A3) then gives

$$
\begin{aligned}
Y^{\dagger}= & P^{C} C-P^{C} \boldsymbol{e} \cdot \boldsymbol{E}+P^{C} b B \\
& +Q^{K}\left(\dot{K}+\dot{K}^{f}\right)+Q^{S} \cdot \dot{\boldsymbol{S}}+Q^{t}
\end{aligned}
$$

which using (A5), (A8) and (A11) gives

$$
=P^{C}\left\{C-\boldsymbol{e} \cdot \boldsymbol{E}+b B+\dot{K}+\dot{K}^{f}+\left(\boldsymbol{Q}^{R}-f_{\boldsymbol{R}}\right) \cdot \dot{\boldsymbol{S}}\right\}+Q^{t} .
$$

If the problem is autonomous, time is "unproductive", so its value $Q^{t}$, the last term of (A13), disappears. If not, first use (A1) and (A4) to get

$\partial Y / \partial t=Q^{K} F_{t}+Q^{K} \dot{\boldsymbol{Q}}^{R} \cdot\left(\boldsymbol{R}^{X}-\boldsymbol{R}^{M}\right)$

which, after using (A5), (A6) and (A10) becomes $\partial Y / \partial t=P^{C}\left[F_{t}+\dot{\boldsymbol{Q}}^{R} \cdot\left(\boldsymbol{R}^{X}-\boldsymbol{R}^{M}\right)\right]$, hence from (5), $Q^{t}(t):=\int_{t}^{\infty} P^{C}(s)\left[F_{s}+\dot{\boldsymbol{Q}}^{R} \cdot\left(\boldsymbol{R}^{X}-\boldsymbol{R}^{M}\right)\right](s) \mathrm{e}^{-r(s-t)} \mathrm{d} s$

From the Divisia property, $\dot{\mathbf{P}} \cdot \mathbf{C}=\dot{P}^{C} C+$ $\sum \dot{\boldsymbol{P}}^{E j} E^{j}+\dot{P}^{B} B=0$

$$
\begin{aligned}
& (\mathrm{A} 6) \Rightarrow P^{E j}=-e^{j} P^{C} \Rightarrow \dot{P}^{E j}=-e^{j} \dot{P}^{C}-\dot{e}^{j} P^{C} \\
& (\mathrm{~A} 7) \Rightarrow P^{B}=P^{C} b \\
& \Rightarrow \dot{P}^{B}=\dot{P}^{C} b+P^{C} \dot{b} \\
& \Rightarrow \dot{P}^{C}(C-\boldsymbol{e} \cdot \boldsymbol{E}+b B)=P^{C}(\dot{\boldsymbol{e}} \cdot \boldsymbol{E}-\dot{b} B) \\
& \Rightarrow \dot{P}^{C} / P^{C}=(\dot{\boldsymbol{e}} \cdot \boldsymbol{E}-\dot{b} B) /(C-\boldsymbol{e} \cdot \boldsymbol{E}+b B)
\end{aligned}
$$

However, in absence of any reliable data, all $e^{j}$ and $b$ are assumed constant, so from (A15), $P^{C}$ is constant, too. Without loss of generality we set $P^{C}=1$, transforming (A13) and (A14) into

$$
\begin{aligned}
Y^{\dagger}= & C-\boldsymbol{e} \cdot \boldsymbol{E}+b B+\dot{K}+\dot{K}^{f}+\left(\boldsymbol{Q}^{R}-f_{\boldsymbol{R}}\right) \cdot \dot{\boldsymbol{S}} \\
& +Q^{t} \text { which is }(13) ; \text { and }
\end{aligned}
$$


Table 2

Estimates of marginal damage costs of pollutants

\begin{tabular}{|c|c|c|c|c|c|}
\hline Pollutant & $\begin{array}{l}\text { Original } \\
\text { value(s) in } \\
£ / \text { tonne }\end{array}$ & $\begin{array}{l}\text { Year, original } \\
\text { currency }\end{array}$ & $\begin{array}{l}\text { Adjustment } \\
\text { factor to } 1999 \\
\text { prices }\end{array}$ & $\begin{array}{l}\text { Value(s) in } \\
1999 \text { £/tonne }\end{array}$ & $\begin{array}{l}\text { MDC used } \\
\text { in } 1999 \\
\text { £/tonne } \\
\end{array}$ \\
\hline \multirow[t]{3}{*}{$\mathrm{SO}_{2}$} & 4940 & 1996, euro & 1.25 & 6175 & \\
\hline & 4500 & 2000 , euro & 1.64 & 7380 & \\
\hline & 6089 & $1998, £$ & 1.024 & 6235 & 6597 \\
\hline \multirow[t]{3}{*}{ PM10 } & 30500 & 1996, euro & 1.25 & 38125 & \\
\hline & 20000 & 1997, £ & 1.053 & 21060 & \\
\hline & 3874 & 1998, £ & 1.024 & 3967 & 21051 \\
\hline $\mathrm{N}_{2} \mathrm{O}$ & $380-3420$ & 1997, £ & 1.053 & $400-3601$ & 2001 \\
\hline \multirow[t]{2}{*}{$\mathrm{CO}$} & 2 & 1998 , euro & 1.48 & 3 & \\
\hline & 7 & 1993, ecu & 1.28 & 9 & 6 \\
\hline $\mathrm{CH}_{4}$ & $35-150$ & $1997, £$ & 1.053 & $37-158$ & 97 \\
\hline \multirow{2}{*}{$\mathrm{CO}_{2}$} & $1.2-9$ & 1997, £ & 1.053 & $1.3-9.5$ & \\
\hline & $3-6$ & 2002, £ & 0.96 & $2.9-5.8$ & 5 \\
\hline
\end{tabular}

$Q^{t}(t):=\int_{t}^{\infty}\left[F_{s}+\dot{\boldsymbol{Q}}^{R} \cdot\left(\boldsymbol{R}^{X}-\boldsymbol{R}^{M}\right)\right](s) \mathrm{e}^{-r(s-t)} d s$

which is (14).

\section{Appendix B. Estimates of marginal damage costs of pollutants}

For all pollutants considered, we used data for marginal damage costs (MDC) rather than for marginal abatement costs, because the former were either the only available, or the more reliable data. This follows the convention proposed in Section 3.3. The marginal damage costs were taken from a literature review, with a range of studies used to derive a value for each air pollutant. Wherever possible estimates for the UK were used. For some pollutants such as carbon monoxide and methane, the literature is limited, whilst for carbon dioxide and sulphur dioxide there is a wide literature. The studies chosen were those considered relevant by the European Union (COWI, 2000). The pollutants $\mathrm{PM} 10, \mathrm{SO}_{2}$ and $\mathrm{CO}$ were valued by the ExternE methodology. That is, a linear dose-response function was used to quantify physical effects, and a valuation of years of statistical life lost was estimated. Morbidity costs were based on the cost of hospital stays, emergency visits, restricted activity days, symptom days, asthma attacks and bronchitis attacks (Rabl et al., 1998; Maddison, 1998; ETSU, 1996). Although only human mortality and morbidity were considered and some impacts were excluded, this technique is considered to be highly relevant for the analysis of these pollutants (COWI, 2000).

Data for the three greenhouse gas pollutants $\left(\mathrm{N}_{2} \mathrm{O}\right.$, $\mathrm{CH}_{4}$ and $\mathrm{CO}_{2}$ ) are from Fankhauser (1995). He used a form of impact pathway looking at temperature damages, based on global warming potential (which takes account of the durability of each gas in the global atmosphere) as outlined by the IPCC. In the case of $\mathrm{CO}_{2}$, an aggregation study (Pearce, 2003) was also used, and was considered to be representative of the range of results from previous studies.

Where more than one study existed for a pollutant, an average of the results was used. For other pollutants a range of possible values was given, and the average of the bottom and top range was used. Table 2 shows the values of each pollutant derived from the above studies, and the resulting mid-range value for MDC chosen for our analysis here.

\section{References}

Asheim, G.B., 2003. Green national accounting for welfare and sustainability: a taxonomy of assumptions and results. Scottish Journal of Political Economy 50 (2), 113-130.

Asheim, G.B., Weitzman, M.L., 2001. Does NNP growth indicate welfare improvement? Economics Letters 73, 233-239.

Atkinson, G., Dubourg, R., Hamilton, K., Munasinghe, M., Pearce, D., Young, C., 1997. Measuring Sustainable Development: Macroeconomics and the Environment. Edward Elgar, Cheltenham, UK. 
Brekke, K.A., Howarth, R.B., 2002. Status, Growth and the Environment: Goods as Symbols in Applied Welfare Economics. Edward Elgar, Cheltenham, UK.

Bruvoll, A., Faehn, T., Strom, B., 2003. Quantifying central hypotheses on the Environmental Kuznets Curve for a rich economy. Scottish Journal of Political Economy 50 (2), $149-173$.

COWI, 2000. A study on the economic valuation of environmental externalities from landfill disposal and incineration of waste. Report to EC DG Environment. COWI, Denmark.

Crafts, N., O'Mahony, M., 2001. A perspective on UK productivity performance. Fiscal Studies 22 (2), 271-306.

Dasgupta, P., 2001. Valuing objects and evaluating policies in imperfect economies. Economic Journal 111 (471), C1-C29.

ETSU (Energy Technology Support Unit), 1996. Economic evaluation of the draft incineration directive. Report to DG XI of the European Comission. ETSU, Harwell, UK.

Fankhauser, S., 1995. Valuing Climate Change-The Economics of the Greenhouse. Earthscan Publications, London.

Gibson, H., Riddington, G., Whigham, D., Whyte, J., 1997. Caledonian Blue Book 1997. Glasgow Caledonian University, Glasgow, Scotland.

Hamilton, K., 1996. Pollution and pollution abatement in the national accounts. Review of Income and Wealth 42 (1), 13-33.

Hamilton, K., Atkinson, G., 1996. Air pollution and green accounts. Energy Policy 24 (7), 675-684.

Hamilton, K., Clemens, M., 1999. Genuine savings rates in developing countries. World Bank Economic Review 13 (2), 333-356

Hanley, N., Atkinson, G., 2003. Economics and sustainable development: what have we learnt, and what do we still need to learn? In: Berkhout, F., Leach, M., Scoones, I. (Eds.), Negotiating Environmental Change: New Perspectives from Social Science. Edward Elgar, Cheltenham, UK.

Hanley, N., MacMillan, D., Wright, R.E., Bullock, C., Simpson, I., Parsisson, D., Crabtree, B., 1998. Contingent valuation versus choice experiments: estimating the benefits of Environmentally Sensitive Areas in Scotland. Journal of Agricultural Economics 49 (1), $1-15$.

Hanley, N., Moffatt, I., Faichney, R., Wilson, M., 1999. Measuring sustainability: a time series of alternative indicators for Scotland. Ecological Economics 28, 55-73.

Hanley, N., McGregor, P., Swales, K., Turner, K.R., 2004. Do increases in resource productivity improve environmental quality? Theory and evidence from an energy-economy-environment regional computable general equilibrium model of Scotland. Typescript, Department of Economics, University of Stirling, and Presented to 2004 EAERE Conference, Budapest, Hungary.
Hartwick, J.M., 1990. Natural resources, national accounting and economic depreciation. Journal of Public Economics 43, $291-304$

HM Treasury,, 1997. Economic Appraisal in Central Government: A Technical Guide. HMSO, London.

Hokby, S., Soderqvist, T., 2003. Elasticities of demand and willingness to pay for environmental services in Sweden. Environmental \& Resource Economics 26 (3), 361-383.

Howarth, R.B., 1996. Status effects and environmental externalities. Ecological Economics 16 (1), 25-34.

Maddison, D., 1998. Valuing changes in life expectancy in England and Wales caused by ambient concentrations of particulate matter. Paper GEC 98-06. Centre for Social and Economic Research on the Global Environment, University College London.

ONS (Office for National Statistics),, 1998. United Kingdom National Accounts: Concepts, Sources and Methods. The Stationery Office, London.

Pearce, D., 2003. The social cost of carbon and its policy implications. Oxford Review of Economic Policy 19 (3), 362-384.

Pemberton, M., Ulph, D., 2001. Measuring income and measuring sustainability. Scandinavian Journal of Economics 103 (1), 25-40.

Peskin, H.M., Delos Angeles, M.S., 2001. Accounting for environmental services: contrasting the SEEA and the ENRAP approaches. Review of Income and Wealth 47 (2), 203-219.

Pezzey, J.C.V., 1997. Sustainability constraints versus 'optimality' versus intertemporal concern, and axioms versus data. Land Economics 73 (4), 448-466.

Pezzey, J.C.V., 2004. One-sided sustainability tests with amenities, and changes in technology, trade and population. Journal of Environmental Economics and Management 48 (1), 613-631.

Pezzey, J.C.V., Toman, M.A., 2002. Progress and problems in the economics of sustainability. In: Tietenberg, T., Folmer, H. (Eds.), International Yearbook of Environmental and Resource Economics 2002/3. Edward Elgar, Cheltenham, pp. 165-232.

Rabl, A., Spadaro, J.V., McGavran, P.D., 1998. Health risks of air pollution from incinerators: a perspective. Waste Management \& Research 16, 365-388.

Senhadji, A., 2000. Sources of economic growth: an extensive growth accounting exercise. IMF Staff Papers 47 (1), 129-157.

Turner, K.R., 2003. A pilot study on constructing a Scottish sectoral $\mathrm{CO}_{2}$ emissions account. Fraser of Allan Institute Quarterly Economic Commentary 28 (3), 43-51.

Vincent, J.R., Panayotou, T., Hartwick, J.M., 1997. Resource depletion and sustainability in small open economies. Journal of Environmental Economics and Management 33, 274-286.

Weitzman, M.L., 1997. Sustainability and technical progress. Scandinavian Journal of Economics 99 (1), 1-13. 